\title{
The vanadium redox cycle: biological and mineralogical considerations in diffusion-limited environments
}

\footnotetext{
MACON J. Abernathy ${ }^{1}$, SAMANTha C. Y ING ${ }^{2}$

${ }^{1}$ Environmental Toxicology, University of California, Riverside, CA 92521; maber001@ucr.edu

${ }^{2}$ Environmental Sciences, University of California, Riverside,

CA 92521; samying@ucr.edu

Mounting evidence of the adverse effects of $\mathrm{V}(\mathrm{V})$ in humans has spurred its addition onto the USEPA's Contaminant Candidate List at a notification level of $50 \mu \mathrm{g} \mathrm{L}-$ ${ }^{1}$. Groundwater concentrations of $\mathrm{V}$ surpass this notification level in multiple regions throughout the state of California, with the highest concentrations found in the Central Valley. Fluctuations in the water tables below these regions as a result of extraction and precipitation events lead to variations in redox conditions that enhance or inhibit the release of $\mathrm{V}$ from sediments into the groundwater. While it is typically present in the $+3,+4$ or +5 oxidation state, the solubility and mobility of $\mathrm{V}$ is highly dependent on its speciation, increasing with charge. As a result, V(IV) and V(V) are the dominant species encountered in groundwater. In this study, we investigate coupled redox interactions that influence the partitioning of $\mathrm{V}$ between its +4 and +5 oxidation states. Using a multi-chamber reactor design, we mimic a diffusionlimited sediment environment from which both aqueous and solid-phase time-series samples can be aquired. To simulate competative processes that lead to redox cycling of $\mathrm{V}$, dissimilatory metal reducing bacteria (Shewanella oneidensis) and common environmental oxidants (Mn(III/IV) oxides) were selected for placement in each of two chambers. To examine the effect of different oxidant types on the partitioning of $\mathrm{V}$ between the +4 and +5 oxidation states, we ran parallel experiments where $\mathrm{V}$ (IV) oxidation was mediated by the reduction of either hexagonal birnessite or manganite. In both cases $\mathrm{V}(\mathrm{V})$ reduction was mediated by $S$. oneidensis relying on lactate as an electron donor. Solid-phase transformations, as well as the development of secondary $\mathrm{V}$ and $\mathrm{Mn}$ phases, were tracked by X-ray absorption spectroscopy, while aqueous methods were used to quantify the rates of $\mathrm{V}$ transformation. The results of this study provide much needed data on the relative influence of biological and mineralogical processes on the transformation of $\mathrm{V}$ in the environment, with implications for groundwater quality.
} 